\title{
Articles
}

\section{Attributions for Performance: A Comparative Study of Japanese and Thai University Students}

\section{Setsuko Mori}

Kinki University

Peter Gobel

Kyoto Sangyo University

Kitcha Thepsiri

\section{King Mongkut's University of Technology Thonburi Punjaporn Pojanapunya}

\section{King Mongkut's University of Technology Thonburi}

Attribution theory posits that people look for causes for their successes and failures. Past research indicates that these causal attributions may influence future performance, and it has been suggested that attributional tendencies may be affected by culture and outcome. To understand the role that culture and outcome may play in attributions for foreign language learning, a set of questionnaires was designed to investigate how EFL university students ( 355 Thai and 350 Japanese) in two countries judged their successes and failures on actual language learning tasks. Although there were a few differences based on culture, MANOVA results revealed that both groups focused more on external factors (such as teachers and classroom atmosphere) for success and internal factors (such as lack of ability and effort) for failure. The impli-

JALT Journal, Vol. 32, No. 1, May 2010 
cations that can be drawn with regard to cultural bias, language teaching, and the nature of the learning environment are considered.

帰属理論は、人は成功や失敗を認知する際、原因帰属を試みるとする。関連の先行研究で は、原因帰属は文化や行為の結果に左右され、ひいては未来の行動に影響を与えるという可能 性が示唆されている。本論文は、異なる文化背景をもつ英語学習者がその学習体験における成 功と失敗の原因を何に求めるかを検証したものである。英語学習者の原因帰属プロセスを検証 するにあたり、タイおよび日本の大学 1 年生 (各 355 人、 350 人)を対象に質問調査を実施した。 その結果、両国の大学生はどちらも、成功の原因は教員やクラスの雾囲気等の外的要因に求 め、失敗の原因は能力不足や努力不足といった内的要因に求めることがわかった。こ㧈らの類 似する原因帰属パターンを文化的な影響によるものと仮定し、英語学習においてどのような影 響を与えるのかについても考察した。

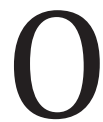

ne of the most widely discussed issues in both educational and social psychology is the power of people's beliefs. What students believe, and how they interpret past behavior and actions, may be reasonably assumed to have an effect on their current and future actions (Dörnyei, 2001). In the area of language learning, many psychologists tend to question why some learners are more successful than others. From the point of view of this important query, learners' attributions for their own success and failure are one issue that researchers need to take into consideration. This paper focuses on a survey of attributions for doing well or poorly on classroom tasks in an EFL setting, and was administered to 705 students at two universities in two countries-Japan and Thailand. The paper begins with background information pertinent to the creation of the survey instruments, including a brief overview of attribution theory, and a review of attribution studies in the field of second language acquisition. Statistical results for the present study are then discussed, with an emphasis on their relationship to the theoretical background presented above. Finally, what the results of the study may tell us about language learning in different cultural contexts is considered.

\section{Review of the Literature}

\section{Attribution Theory in Mainstream Psychology}

In mainstream psychology, many researchers have tried to understand achievement behavior through analyzing perceived causes of success or failure (Burke, 1978; Elig \& Frieze, 1979; Weiner, 1979; Weiner, et al., 1971). Research in this area has sought to identify the types of causal attributions people make to explain successes and failures in occupational and educational settings, and how these attributions affect expectations for future success or failure. 
Attribution theory (Weiner, 1979) suggests that individuals have a need to either find or manufacture reasons for why a particular outcome occurs. These reasons may then have a significant effect on future action, motivation, and achievement strivings. These attributions are used to answer internal and external questions related to performance and are frequently posed in the negative since people are more likely to be concerned about negative or unexpected outcomes in an attempt to either save face or control future outcomes. Most attempts to test attribution theory have dealt with four types of causal explanations for success or failure: (a) ability, (b) effort, (c) luck, and (d) task ease or difficulty (e.g., Bruning, Schraw, \& Ronning, 1999; Dörnyei \& Murphey, 2003; Hsieh \& Schallert, 2008; Weiner et al., 1971). In addition, an outcome might also be attributed to a number of other factors including other people (such as teachers or other students), mood, fatigue or illness, personality, and physical appearance (Weiner, 1986).

We can see, then, how attributions of causality may vary from person to person and task to task, but they also vary from culture to culture, and they vary from social group to social group as well (Graham, 1991). Despite these differences in perceived causes for success or failure, all of these causal attributions can be quantitatively compared in terms of a set of underlying properties, or causal dimensions (Weiner, 1979). Weiner argued that the motivational dimensions of attribution could be described as a causal structure consisting of three parts: (a) locus, (b) stability, and (c) control. The locus of causality is concerned with whether a cause is perceived as being internal or external to the individual. For instance, ability and effort could be classified as internal, whereas task difficulty and luck would be classified as external. The stability dimension refers to whether a cause is fixed and stable, or variable and unstable over time. In this case, ability would be seen as stable, with effort being unstable or variable over time. Finally, controllability indicates how much control a person has over a cause. The effect of either luck or weather would be uncontrollable by an athlete, for example.

In attribution theory, these three dimensions form the basis of the taxonomy used to classify the specific causes of any success or failure. For instance, ability and effort, the two most commonly perceived causes in Western culture, can be thus classified within the cells of a Locus x Stability $\mathrm{x}$ Control matrix. This means that failure due to low ability is perceived as a characteristic of the failing individual, endures over time, and is beyond personal control. Effort, on the other hand, indicates a cause that is internal, unstable, and controllable. 


\section{Attribution Theory in Educational Contexts}

In the field of education, a number of studies have investigated student attributions regarding test performance (Marsh, 1984; Meyer \& Koelbl, 1982), past and future task performance (Burke, 1978; Farmer, Vispoel, \& Maehr, 1991; Frieze \& Snyder, 1980; Little, 1985; Pancer, 1978; Vispoel \& Austin, 1995), the relationship between causal attributions and expectancy (Betancourt \& Weiner, 1982), causal attributions and gender (Bar-Tal, Goldberg, \& Knaani, 1984; Farmer \& Vispoel, 1990; Pintrich \& Schunk, 2002; Travis, Burnett-Doering, \& Reid, 1982) and teacher expectation and causal attributions (Cooper \& Burger, 1980; Seegers, Van Putten, \& Vermeer, 2004). The majority of these studies were concerned with the school milieu in general, analyzing attributions and performance across academic subjects as well as other school activities. For example, Vispoel and Austin (1995) looked at junior high school students' recollection of successes and failures in the areas of English, math, music, and physical education, noting strong connections between causal beliefs and classroom achievement. Although the results of the cited studies differ to some degree, they have highlighted not only the importance of attributions of ability, effort, luck, and task, but also have shown how these various attributions can be interpreted in terms of the dimensions of locus, stability, and control (see Table 1).

\section{Table 1. Dimensional Classification Scheme for Causal Attributions}

\begin{tabular}{cccc}
\hline \multirow{2}{*}{ Attribution } & Locus & Stability & Controllability \\
\hline Ability & Internal & Stable & Uncontrollable \\
Effort & Internal & Unstable & Controllable \\
Strategy & Internal & Unstable & Controllable \\
Interest & Internal & Unstable & Controllable \\
Task difficulty & External & Stable & Uncontrollable \\
Luck & External & Unstable & Uncontrollable \\
Family influence & External & Stable & Uncontrollable \\
Teacher influence & External & Stable & Uncontrollable \\
\hline
\end{tabular}

From Vispoel \& Austin (1995), based on Weiner (1979) 
These results support early theories that attempt to explain why some attributions facilitate success or failure more than others. Weiner (1979, 1986) has proposed that internal attributions produce greater changes in esteem-related affect than external attributions, stable attributions are more concerned with expectancy for success or failure, and controllable attributions are more closely connected with persistence than uncontrollable attributions. From early studies the existence of these causal dimensions was accepted despite a lack of empirical evidence, the nature of open-ended questionnaire and interview-generated data precluding detailed quantitative analysis. However, in recent years the use of factor analysis and multidimensional scaling has provided some support for their existence (Hsieh \& Schallert, 2008; Meyer, 1980; Meyer \& Koelbl, 1982; Vispoel \& Austin, 1995).

\section{Attribution Theory in a Foreign Language Context}

Although a great number of people spend a considerable amount of time studying foreign languages, very few are likely to reach a reasonable level of second language (L2) proficiency. As a result, language learning, in many people's minds, is associated with failure, risk taking, and losing face (Horwitz, 1988). In addition, learning a foreign language challenges students by forcing them to integrate and assimilate new cultural practices (Williams \& Burden, 1997). For these reasons, attribution theory is a relevant research area in the L2 field. Skehan (1989), for example, called for more attribution theory research, suggesting the possibility of synthesizing many of the individual variables associated with language learning into a more coherent account of the language learning process.

Given the theoretical significance of attributions in L2 motivation, it is actually surprising how little research has been conducted. There may be many reasons for this. For one thing, causal attributions are quite complex, and this affects the design of the study: broad questionnaires focusing on linear relationships and broad categories do not adequately portray the intricacy of the attributional process. Nevertheless, a few researchers have provided insight into the $\mathrm{L} 2$ causal attribution process.

In their study of L2 learners of French, Williams and Burden (1999) found that the British primary school children interviewed attributed success to external factors, with the number of attributions increasing with age. Younger children tended to focus on listening and concentrating as causes for doing well, while older children cited effort and interest among reasons for doing well. They also found that many of the attributions mentioned were strongly connected to teacher influence. 
In a study of 51 American undergraduate and graduate foreign language students, Tse (2000) suggested that the main attributions for success in foreign language learning were the teachers' willingness to help students, a positive classroom environment, family or community assistance from target language speakers, and motivation to learn. Attributions for failure included lack of study or insufficient motivation, and mixed-level classes.

Williams, Burden, and Al-Baharna (2001) uncovered 11 positive and 18 negative attributions among 25 students learning English in Bahrain. They found that the main attributions for success included practice, support from family, and a positive attitude, while teaching methods, lack of support from family and teachers, poor comprehension, and a negative attitude were cited as the most common negative attributions.

In her qualitative study of university learners of French, Ushioda (2001) cited four attributional patterns among the learners: attributing positive L2 outcomes to personal ability or personal qualities; attributing negative L2 outcomes to temporary shortcomings that may be changed; attributing negative affective experiences to the learning context; and attributing future success or changes in behavior to personal resources. Ushioda noted that these attributions may act as a filter through which the learner views positive or negative experiences in such a way as to maintain a positive selfconcept.

In another study on foreign language learning among 285 adolescent students in the UK, Williams, Burden, Poulet, and Maun (2004) identified 21 attributional categories, with the major reasons for doing well cited as effort, strategy, ability, teacher, interest, task, and peers. One interesting finding was that the majority of attributions for both success and failure were considered internal. They also found clear differences in attribution for success and failure based on gender, year groups, and language studied.

In an effort to provide a more accurate representation of learner attributions, Kalaja (2004) and Heikinnen (1999) used a discursive model to look at individual narratives of students' language learning histories, attempting to link student beliefs and causal attributions to explain their performance in EFL learning. They came up with a group of five interpretive repertoires, or ways in which students construct the learning environment and their roles as learners: (a) individualistic, (b) effort, (c) naturalistic, (d) institutional, and (e) fatalistic. These repertoires were then connected to the following attributions: (a) personal abilities, (b) effort, (c) informal contexts (taking advantage of opportunities), (d) formal contexts (the classroom), and (e) luck. Isomöttönen (2003) used a similar research approach in looking at 
hard-of-hearing learners of EFL and came up with similar results, although additional repertoires were added due to the nature of the learners.

Hsieh and Schallert (2008) attempted to combine two motivational constructs, self-efficacy and attribution, to explore the motivation of 500 undergraduate foreign language learners in the US. The students were asked to consider their test scores in light of these two constructs, and give actual reasons for the outcome. Analysis suggested that self-efficacy was the strongest predictor of achievement, supplemented by ability attributions.

It must be noted that, with the exception of the last study, all of the FL studies mentioned here used data gathered through open-ended questionnaires, interviews, or autobiographies. The analysis, then, tended towards the qualitative, rather than the quantitative, which may help to explain the variety in the number of attributional categories uncovered, as well as the differences in the findings, making it difficult to compare groups or generalize findings. In addition, many of the studies employed role-playing methods to gather data (creating hypothetical situations), rather than measuring actual behavior. This prompted the authors to move the research in a more quantitative direction, with a particular task in mind, which would allow the use of larger numbers of participants and more sophisticated statistical procedures.

With these reference points, a study was carried out to explore perceived reasons for successes and failures in speaking and reading classes among 1st-year Japanese university students (Gobel \& Mori, 2007). The results revealed that students who reported performing poorly attributed poor performance to a lack of ability and lack of effort. On the other hand, students who reported performing well attributed their performance to teachers and the classroom atmosphere. This finding was contrary to much of the research done to date. Since most of the previous research had been done in Western countries, it was hypothesized that the results might be explained by cultural differences.

In fact, cultural differences in attributional patterns have been reported in mainstream psychology (e.g., Betancourt \& Weiner, 1982) and general education (e.g., Sivanes, 2006). The authors were curious to know if the results of Gobel and Mori (2007) would extend to other Asian countries. Comparative studies in foreign language education can be difficult due to differences in language learning goals and curriculum, for example. However, a study done by Thepsiri and Pojanapunya (2008) convinced the authors that the English education curricula of Thailand and Japan, as well as the importance of learning English in both countries, were similar enough to warrant a com- 
parative study. It was hypothesized that similarities between Thailand and Japan would be evident in student attributions of success and failure, and that the results of the comparative study would differ from results of previous foreign language learning studies undertaken in the West. To explore this possibility, the following research questions were formulated:

1. To what factors do Thai and Japanese students attribute their successes and failures?

2. Are there differences in attributional response based on country (Thailand and Japan)?

3. Are there differences in attributional response based on outcome (success and failure)?

\section{Method}

\section{Participants}

Participants in this study were 705 university students from Thailand and Japan. The Thai participants were a total of 355 first-year students (193 female and 162 male) attending an autonomous state university in Bangkok. Most were majoring in engineering; none were language majors. All students already had a minimum of 6 years of exposure to English as a foreign language in primary and secondary education. At this university, the students have to take at least three compulsory integrated-skill task-based English courses in which all four language skills are studied simultaneously depending on the nature of each task. They meet twice a week for two periods of 50 minutes. The teachers use in-house materials designed by the department staff based on the principles of task-based learning.

The Japanese participants were a total of 350 first-year university students (121 female and 229 male) attending a private university in Kyoto. Their fields of study included law, business, economics, and sciences. Although they were not language majors either, they were taking required English courses just like their Thai counterparts. The required English course curriculum consisted of reading classes and oral communication classes. These classes met twice a week. The reading classes were taught by Japanese teachers of English, and the oral English classes were taught by native speakers of English. Each teacher had a choice of textbooks and teaching styles, but had to follow the guidelines for goals and objectives set by the university.

As described above, the actual contents of the classes and teaching methods may have been different. However, the Thai and Japanese participants 
were comparable in that both groups were 1st-year non-English majors studying English as a foreign language in required classes, had similar curriculum and class environments (e.g., class size), shared similar past learning experience (6 years in junior and senior high schools), and had general English proficiency levels varying from beginner to upper intermediate.

\section{Measure}

Two versions of a questionnaire were created based on previous research (Vispoel \& Austin, 1995) and our research questions: one version asked about successful experience whereas the other asked about unsuccessful experience (see Appendix for the translation of the questionnaire). Both versions of the questionnaire were administered in participants' native languages after they were forward-and-backward translated by experienced translators from English to Thai, and from English to Japanese.

Both versions of the questionnaire consisted of two parts. In the first part, the students were asked to choose an activity from a list of 25 activities which they were either particularly successful at, or at which they performed particularly poorly in the previous semester. Although those activities were roughly divided into four skills, they were instructed to choose only one activity in order to avoid complications in the subsequent statistical analyses. The main purpose of this section was to help the students focus on a particular activity rather than thinking of learning English in general when identifying attributions for success and failure.

In the second part, the students were then asked to rate the importance of the 12 statements provided as reasons why they might have done well or poorly on a given activity on a 6-point Likert scale. Those 12 attributions were labeled: (a) ability (I have strong/weak skills in English), (b) effort (I tried/didn't try very hard), (c) strategy (I used the right/wrong study or practice methods), (d) interest (I had interest/no interest in the activity), (e) luck (I had good/bad luck), (f) teacher influence (The teacher's instruction was appropriate/inappropriate), (g) task difficulty (The task was easy/difficult), (h) class atmosphere (I liked/didn't like the atmosphere of the class), (i) interest in grades (I had interest/no interest in getting a good grade), (j) preparation (I was well-prepared/ill-prepared), (k) enjoyment (I like/ don't like English), and (l) class level (The level of the class was appropriate/ inappropriate). 


\section{Procedure}

Both the Thai and the Japanese participants answered the attribution questionnaire in their required English classes at the end of their semester. The participants were divided into two groups. Pertaining to their language learning experience over the last semester, one group was asked about successful activities and reasons for success while the other group was asked about unsuccessful activities and reasons for failure. The division into two groups was to avoid any unnecessary confusion that might occur if they were asked about both successful and unsuccessful experiences at the same time. The way of dividing the students was slightly different between the Thai and Japanese sections. In the Thai section, half the class focused on successful learning activities, while the other half focused on unsuccessful ones. On the other hand, in the Japanese section, entire classes were randomly assigned to complete a questionnaire regarding either success or failure. At both sites the questionnaire was completed within 15-20 minutes.

\section{Data Analysis}

The data from the completed questionnaires was entered into a Microsoft Excel spreadsheet and checked for accuracy. To determine the effects of country (Thailand and Japan) and outcome (success and failure) on attribution scales, multivariate analysis of variance (MANOVA) was performed. MANOVA is an extension of analysis of variance and used with multiple, dependent variables.

\section{Results}

\section{Perceived Successful and Unsuccessful Activities}

In the first section of the questionnaire, the students were asked to choose one successful activity or one unsuccessful activity. As mentioned earlier, this question was included so that the students could focus on one specific activity, rather than English learning as a whole, when answering the attribution questions in the subsequent section of the questionnaire. Although the kinds of activities chosen and their effects on attributions were not closely examined in this study, for reference purposes the results are presented in Table 2. 
Table 2. Frequency of Reported Successful and Unsuccessful Activities by Country

\begin{tabular}{|c|c|c|c|c|}
\hline \multirow[t]{2}{*}{ Reported activities } & \multicolumn{2}{|c|}{ Successful } & \multicolumn{2}{|c|}{ Unsuccessful } \\
\hline & Thai & Japanese & Thai & Japanese \\
\hline $\begin{array}{l}\text { Reading texts using appropri- } \\
\text { ate strategies }\end{array}$ & 37 & 3 & 22 & 2 \\
\hline $\begin{array}{l}\text { Answering comprehension } \\
\text { questions }\end{array}$ & 29 & 11 & 15 & 2 \\
\hline Learning vocabulary & 27 & 8 & 8 & 11 \\
\hline Understanding grammar & 23 & 6 & 5 & 8 \\
\hline $\begin{array}{l}\text { Translating texts and passages } \\
\text { from English }\end{array}$ & 8 & 17 & 5 & 9 \\
\hline $\begin{array}{l}\text { Reading and summarizing } \\
\text { texts }\end{array}$ & 7 & 10 & 4 & 7 \\
\hline Quizzes and exams (Reading) & 4 & 5 & 3 & 5 \\
\hline Other (Reading) & 0 & 1 & 1 & 1 \\
\hline Reading total & 135 & 61 & 63 & 45 \\
\hline $\begin{array}{l}\text { Understanding a listening } \\
\text { passage using appropriate } \\
\text { strategies }\end{array}$ & 12 & 5 & 17 & 7 \\
\hline $\begin{array}{l}\text { Listening and repetition/ } \\
\text { dictation }\end{array}$ & 5 & 17 & 10 & 13 \\
\hline Listening and note taking & 5 & 2 & 8 & 14 \\
\hline Quizzes and exams (Listening) & 4 & 3 & 7 & 13 \\
\hline Other (Listening) & 0 & 0 & 2 & 1 \\
\hline Listening total & 26 & 27 & 44 & 48 \\
\hline $\begin{array}{l}\text { Giving a presentation and/or } \\
\text { speech }\end{array}$ & 12 & 7 & 26 & 13 \\
\hline Role play & 7 & 6 & 4 & 1 \\
\hline $\begin{array}{l}\text { Giving opinions/sharing ideas } \\
\text { in class/groups }\end{array}$ & 3 & 31 & 4 & 11 \\
\hline
\end{tabular}




\begin{tabular}{lrrrr}
\hline Reported activities & \multicolumn{2}{c}{ Successful } & \multicolumn{2}{c}{ Unsuccessful } \\
\hline & Thai & Japanese & Thai & Japanese \\
\hline Answering teacher's questions & 1 & 12 & 3 & 19 \\
Exams (Speaking) & 1 & 12 & 1 & 6 \\
Other (Speaking) & 0 & 0 & 0 & 1 \\
Speaking total & $\mathbf{2 4}$ & $\mathbf{6 8}$ & $\mathbf{3 8}$ & $\mathbf{5 1}$ \\
Writing a summary & 9 & 6 & 16 & 7 \\
Writing paragraphs & 8 & 1 & 5 & 6 \\
Writing diaries and/or port- & & & & \\
folios & 2 & 4 & 4 & 8 \\
Writing a report & 1 & 5 & 3 & 8 \\
Quizzes and exams (Writing) & 1 & 3 & 1 & 1 \\
Other (Writing) & 1 & 0 & 1 & 1 \\
Writing total & $\mathbf{2 2}$ & $\mathbf{1 9}$ & $\mathbf{3 0}$ & $\mathbf{3 1}$ \\
TOTALS & $\mathbf{2 0 7}$ & $\mathbf{1 7 5}$ & $\mathbf{1 7 5}$ & $\mathbf{1 7 5}$ \\
\hline
\end{tabular}

\section{Research Question 1: Attributional Responses Based on Country and Outcome}

Descriptive Statistics

Table 3 shows the means and standard deviations of the attribution category scores based on student responses on the 6-point Likert scale. In rank order based on the total sample means, the four most endorsed success attributions for the Thai students were interest in grades (5.25), teacher influence (4.66), classroom atmosphere (4.42), and effort (4.42), whereas the four most endorsed success attributions for the Japanese were teacher influence (4.22), class level (3.96), classroom atmosphere (3.89), and interest (3.64). Interestingly enough, both the Thai and Japanese students attributed their success to teacher influence and class atmosphere, both of which are defined as external, stable, and uncontrollable attributions according to attribution theory (Weiner, 1979, 1986). In contrast to the results of success attributions, the four most endorsed failure attributions for both the Thai and Japanese students were ability $(3.97,3.17)$, effort $(3.31,4.00)$, strategy $(3.54,3.80)$, and preparation $(3.52,4.13)$, respectively. Again it is interesting 
to note that these failure attributions are all internal attributions (see Table 1).

Table 3. Means and Standard Deviations by Country and Outcome

\begin{tabular}{|c|c|c|c|c|c|c|c|}
\hline $\begin{array}{l}\text { Attribution } \\
\text { scales }\end{array}$ & Country & $N$ & Outcome & Mean & $S D$ & Skewness & Kurtosis \\
\hline \multirow[t]{4}{*}{ Ability } & Thai & 176 & Success & 3.45 & 1.00 & -0.32 & 0.32 \\
\hline & & 180 & Failure & 3.97 & 1.13 & -0.35 & -0.31 \\
\hline & Japanese & 174 & Success & 2.95 & 1.32 & 0.17 & -0.73 \\
\hline & & 175 & Failure & 3.17 & 1.48 & 0.17 & -1.03 \\
\hline \multirow[t]{4}{*}{ Effort } & Thai & 176 & Success & 4.42 & 0.81 & -0.49 & 0.61 \\
\hline & & 179 & Failure & 3.31 & 1.16 & 0.09 & -0.57 \\
\hline & Japanese & 175 & Success & 3.54 & 1.24 & -0.11 & -0.36 \\
\hline & & 174 & Failure & 4.00 & 1.50 & -0.54 & -0.67 \\
\hline \multirow[t]{4}{*}{ Strategy } & Thai & 175 & Success & 3.83 & 0.85 & -0.41 & 0.77 \\
\hline & & 178 & Failure & 3.54 & 0.96 & -0.11 & -0.39 \\
\hline & Japanese & 175 & Success & 3.35 & 1.27 & -0.05 & -0.69 \\
\hline & & 175 & Failure & 3.80 & 1.43 & -0.40 & -0.71 \\
\hline \multirow[t]{4}{*}{ Interest } & Thai & 176 & Success & 4.28 & 0.89 & -0.86 & 1.56 \\
\hline & & 179 & Failure & 2.68 & 1.30 & 0.50 & -0.53 \\
\hline & Japanese & 174 & Success & 3.64 & 1.20 & -0.25 & -0.26 \\
\hline & & 174 & Failure & 2.50 & 1.27 & 0.64 & -0.30 \\
\hline \multirow[t]{4}{*}{ Luck } & Thai & 175 & Success & 3.63 & 1.34 & -0.24 & -0.57 \\
\hline & & 179 & Failure & 2.47 & 1.39 & 0.67 & -0.36 \\
\hline & Japanese & 175 & Success & 3.05 & 1.54 & 0.22 & -0.96 \\
\hline & & 175 & Failure & 1.69 & 1.16 & 2.04 & 3.80 \\
\hline \multirow{4}{*}{$\begin{array}{l}\text { Teacher } \\
\text { influence }\end{array}$} & Thai & 175 & Success & 4.66 & 0.97 & -1.07 & 2.07 \\
\hline & & 180 & Failure & 2.76 & 1.33 & 0.66 & -0.44 \\
\hline & Japanese & 175 & Success & 4.22 & 1.38 & -0.74 & 0.05 \\
\hline & & 175 & Failure & 1.69 & 0.96 & 1.69 & 3.19 \\
\hline \multirow{4}{*}{$\begin{array}{l}\text { Task } \\
\text { difficulty }\end{array}$} & Thai & 176 & Success & 3.28 & 0.96 & -0.06 & 0.72 \\
\hline & & 179 & Failure & 2.88 & 0.97 & 0.24 & -0.17 \\
\hline & Japanese & 174 & Success & 3.57 & 1.29 & -0.09 & -0.62 \\
\hline & & 175 & Failure & 2.73 & 1.26 & 0.36 & -0.57 \\
\hline \multirow{3}{*}{$\begin{array}{l}\text { Class } \\
\text { atmosphere }\end{array}$} & Thai & 176 & Success & 4.42 & 1.03 & -0.42 & 0.06 \\
\hline & & 179 & Failure & 2.77 & 1.28 & 0.60 & -0.23 \\
\hline & Japanese & 175 & Success & 3.89 & 1.62 & -0.35 & -1.03 \\
\hline
\end{tabular}




\begin{tabular}{|c|c|c|c|c|c|c|c|}
\hline $\begin{array}{l}\text { Attribution } \\
\text { scales }\end{array}$ & Country & $N$ & Outcome & Mean & $S D$ & Skewness & Kurtosis \\
\hline & & 175 & Failure & 1.80 & 1.05 & 1.63 & 2.96 \\
\hline \multirow{4}{*}{$\begin{array}{l}\text { Interest in } \\
\text { grades }\end{array}$} & Thai & 176 & Success & 5.25 & 1.06 & -1.82 & 3.70 \\
\hline & & 179 & Failure & 2.94 & 1.70 & 0.53 & -0.90 \\
\hline & Japanese & 175 & Success & 3.42 & 1.24 & -0.22 & -0.63 \\
\hline & & 175 & Failure & 2.20 & 1.23 & 1.19 & 1.19 \\
\hline \multirow[t]{4}{*}{ Preparation } & Thai & 176 & Success & 3.84 & 0.83 & -0.47 & 0.99 \\
\hline & & 179 & Failure & 3.52 & 1.24 & 0.09 & -0.56 \\
\hline & Japanese & 175 & Success & 3.16 & 1.23 & 0.02 & -0.43 \\
\hline & & 175 & Failure & 4.13 & 1.34 & -0.40 & -0.65 \\
\hline \multirow[t]{4}{*}{ Enjoyment } & Thai & 176 & Success & 4.14 & 1.10 & -0.47 & 0.36 \\
\hline & & 179 & Failure & 3.08 & 1.44 & 0.25 & -0.79 \\
\hline & Japanese & 175 & Success & 3.42 & 1.44 & 0.11 & -0.83 \\
\hline & & 175 & Failure & 2.28 & 1.37 & 1.19 & 0.87 \\
\hline \multirow[t]{4}{*}{ Class level } & Thai & 176 & Success & 4.40 & 0.91 & -0.28 & -0.17 \\
\hline & & 180 & Failure & 2.88 & 1.38 & 0.71 & -0.28 \\
\hline & Japanese & 175 & Success & 3.96 & 1.42 & -0.29 & -0.79 \\
\hline & & 175 & Failure & 2.03 & 1.14 & 1.42 & 2.25 \\
\hline
\end{tabular}

\section{Research Questions 2 and 3: Country and Outcome Differences}

A one-way MANOVA was performed to examine the effect of country (Thai and Japanese) and outcome (success or failure) on the 12 attribution scales. Some assumptions underlying MANOVA are multivariate normal distribution and homogeneity of variance-covariance matrices (Green \& Salkind, 2005). Despite a few items with marked skewness and kurtosis, a sample size such as this one, with relatively equal sample sizes between groups, ensures that all assumptions have been met (Tabachnick \& Fidell, 1996). Another assumption, that the scores are independent, has also been met in this study.

As Table 4 shows, the results for the MANOVA indicated a significant main effect for country and outcome on the dependent variables, Wilks's $\Lambda=.69$, $F(12,673)=25.33, p<.00, \eta^{2}=.31$, and Wilks's $\Lambda=.42, F(12,673)=77.19$, $p<.00, \eta^{2}=.58$, respectively. A significant interaction between country and outcome was also seen, Wilks's $\Lambda=.80, F(12,67)=14.22, p<.00, \eta^{2}=.20$. 


\section{Table 4. The Summary of MANOVA Results with Country and Outcome as Independent Variables and Attributions as a Dependent Variable}

\begin{tabular}{lcccccc}
\hline Effect & Value & $F$ & $\begin{array}{c}\text { Hypo- } \\
\text { thesis } d f\end{array}$ & Error $d f$ & Sig. & $\begin{array}{c}\text { Partial Eta } \\
\text { Squared }\end{array}$ \\
\hline Intercept & 0.036 & $1.52 \mathrm{E}+03$ & 12 & 673 & 0.00 & 0.964 \\
Country & 0.689 & $25.331 \mathrm{a}$ & 12 & 673 & 0.00 & 0.311 \\
Outcome & 0.421 & $77.185 \mathrm{a}$ & 12 & 673 & 0.00 & 0.579 \\
Country* & & & & & & \\
Outcome & 0.798 & $14.219 \mathrm{a}$ & 12 & 673 & 0.00 & 0.202 \\
\hline
\end{tabular}

Because the interaction between country and outcome was significant, the researchers chose to ignore the independent variable main effect, and instead examined the differences among attributes for country and outcome separately. To control for Type I error across the main effects, an alpha level of .01was set. Except for effort, strategy, task, and preparation, all comparisons for country were significant at $p<.01$, and all comparisons for outcome except strategy were significant at $p<.01$.

The comparisons of means indicated that the Japanese students had higher attribution ratings than the Thai students on task difficulty, effort, strategy, and preparation. This suggests that Japanese students have a stronger tendency to attribute easiness of task to success, and blame lack of effort and preparation and inappropriate strategy use for failure. For the independent variable of outcome, success attribution ratings were significantly higher than those of failure in terms of ability and preparation. This finding implies that both the Thai and the Japanese students tend to attribute ability and preparation to failure more than success.

\section{Discussion and Conclusion}

The goal of this study was to address gaps in the literature on motivation and language learning by examining the relationship between EFL students' attributions regarding authentic classroom activities and their completion of those activities. It was revealed that attributional responses differed when the students succeeded and failed. Although Thai and Japanese students chose different activities as successful and unsuccessful activities, they showed some striking similarities regarding to what they attributed their successes and failures. First of all, both the Thai and the Japanese students tended to attribute more to successes than to failures. In particular, 
they seemed to focus more on external factors, especially teacher influence and classroom atmosphere, when they succeeded. On the other hand, when they failed, they both seemed to focus more on internal causes, namely lack of ability and effort. This is congruent with the findings of a previous study (Gobel \& Mori, 2007) with Japanese university students. In that study, we also found that the participants did not show the self-enhancement or self-protective tendencies that are widely recognized in cognitive psychology (Krueger, 1998). The self-enhancement tendency refers to individuals' propensity for giving themselves credit when they succeed, and the selfprotective tendency denotes their propensity for blaming others when they fail. A meta-analysis of studies conducted in Japan (Markus \& Kitayama, 1991) confirmed such a self-critical rather than self-enhancing tendency among the Japanese participants and contended that cultural differences may play a part in this. Markus and Kitayama further argued that a number of Western cultures such as those of North America promote independence and autonomy, while many non-Western cultures such as those of Japan and Thailand emphasize interdependence and connectedness among individuals and the group. As a result, in Western cultures the independent self is motivated to maintain autonomy and uniqueness, the individual engaging in self-enhancing biases to support the idea that one is self-sufficient and worthy. In contrast, in interdependent cultures, individuals consider themselves as part of an encompassing social unit, and as a result, are encouraged to adjust behavior to maintain meaningful social relationships (Kitayama, Markus, Matsumoto, \& Norasakkunkit, 1997). In such cultures, modesty and acquiescence are accepted responses, making it unwise for one to stand out or explicitly express self-confidence. In the present study, although the Japanese students attributed lack of effort and preparation, as well as inappropriate strategy use, to failure more than the Thai students did, the results showed a self-critical tendency among both the Thai and Japanese students.

This finding has some important pedagogical implications. Firstly, from the teacher's standpoint, cultural sensitivities must be considered. Teachers from Western countries teaching in non-Western ones should consider the culture when creating tasks and syllabi, as well as when engaging the students. Although most teachers may be aware of cultural differences and take them into account when dealing with areas such as pragmatics, they also need to keep in mind the effect the culture has on a student's view of performance. It cannot simply be assumed that all students have the same perceptions and preferences regarding learning styles, teachers and classroom environments, and classroom activities. 
Secondly, based on Weiner's (1979) dimensional classification, both ability and effort can be categorized as internal attributions. However, the major difference is that the former is considered as stable and uncontrollable whereas the latter is deemed unstable and controllable. According to Weiner, internal attributions produce greater changes in the self-esteem affect than external attributions, stable attributions are more concerned with expectancy for success or failure, and controllable attributions are more closely related to persistence than uncontrollable attributions. Considering this, it seems that our participants' tendency to blame lack of ability for failure is more problematic than their tendency to blame lack of effort. In school settings, for example, it is not hard to imagine that students who continue to fail on a certain task have a lower expectancy for success, and consequently become less persistent on future achievement tasks. Future failure is then seen as unavoidable, and learned helplessness is then reinforced.

There is hope for the student, however. Previous research has suggested that student perseverance is improved when attributions for failure are changed from internal, uncontrollable factors (such as poor ability) to internal and controllable ones (such as lack of effort). If this is true, then teacher feedback and well-designed tasks can be used to help change student attributions. When students perform poorly, a teacher's response can lead them to attribute their behavior to causes that are either facilitative or debilitative. A teacher displaying disgust, for instance, implies a lack of ability on the part of the student, whereas a teacher becoming irritated with a student implies that the student has the ability but has simply not applied it. Similarly, a student could also interpret too much praise or excessive help from teachers as an indication of a low ability. Finally, tasks designed at an appropriate level of difficulty, with clear goals and objectives related to the curriculum, can also encourage students to attribute their failures to unstable, controllable factors-factors that do not guarantee failure in the future.

Current models of L2 acquisition take into account the fact that students' perceptions in the FL classroom can affect learning outcomes. As attributions can influence students' self-efficacy and directly affect their expectations of future success, teachers need to pay attention to how learners view their successes and failures, which is directly related to how they make sense of the learning environment. How students make attributions for their failures, for example, may influence how they approach future tasks. Since attributions are dynamic and permeable, teachers should be able to affect the future causal attributions of students, changing the way students view themselves as learners, how they create their own ideas of success and 
failure, and even how they view themselves and their progress in learning a language. In other words, helping students to view success and failure as outcomes that can be controlled may increase their expectancy for success and lead to actual success in future endeavors.

There were obvious limitations to the present study. First, although the Thai and Japanese students worked on a similar timeline and with similar curricula, the contents of the classes and teaching methodologies were different, which may have affected the results. However, bearing in mind that it is almost impossible to find identical groups with comparative studies such as this one, the similarity between their learning histories and experience lends weight to the results of the study.

Secondly, to avoid the possibility of obscuring the results of statistical analyses, it was decided to have the participants report on only one activity. As a result, it was not possible to take type of activity into consideration when interpreting differences in attributional responses. Although there are limits to self-report studies, the authors have attempted to shed light on causal attributions for success and failure using a more quantitative approach, rather than the interpretive approach used in many of the previous studies in our field (e.g., Ushioda, 2001; Williams \& Burden, 1999).

It is clear that further research is needed. In the meantime, the research reported here reminds us that the classroom is directly connected to a larger social world. It is not within the scope of this paper to address the broader social and political dimensions of motivation, which may change from culture to culture and situation to situation. If anything, the results of this study point toward one important feature of the classroom setting: the teacher's role in developing student awareness of the boundaries and constraints that may affect motivation.

Setsuko Mori is an associate professor at the School of Law, Kinki University. Her research interests include learner motivation, reading, and testing.

Peter Gobel is a professor in the Faculty of Cultural Studies, Kyoto Sangyo University. He researches primarily in the areas of motivation and strategy use.

Kitcha Thepsiri is a lecturer at the School of Liberal Arts, King Mongkut's University of Technology Thonburi. His interests include sociocultural perspectives and task-based learning. 
Punjaporn Pojanapunya is a researcher in the School of Liberal Arts, King Mongkut's University of Technology Thonburi. Her research interests include self-access learning and motivation.

\section{References}

Bar-Tal, D., Goldberg, M., \& Knaani, A. (1984). Causes of success and failure and their dimensions as a function of sex and gender: A phenomenological analysis. British Journal of Educational Psychology, 54, 51-61.

Betancourt, H., \& Weiner, B. (1982). Attributions for achievement-related events, expectancy and sentiments: A study of success and failure in Chile and the U.S. Journal of Cross-Cultural Psychology, 13, 263-374.

Bruning, R. H., Schraw, G. J. \& Ronning, R. R. (1999). Cognitive psychology and instruction (3rd. ed.). Upper Saddle River, NJ: Merrill.

Burke, J. P. (1978). On causal attribution: The interactive relationship between selfesteem and task performance. Social Behavior and Personality, 6, 211-221.

Cooper, H. M., \& Burger, J. M. (1980). How teachers explain students' academic performances: A categorization of free response academic attributions. American Educational Research Journal, 17, 95-109.

Dörnyei, Z. (2001). Motivational strategies in the language classroom. Cambridge: Cambridge University Press.

Dörnyei, Z., \& Murphey, T. (2003). Group dynamics in the language classroom. Cambridge: Cambridge University Press.

Elig, T., \& Frieze, I. (1979). Measuring causal attributions for success and failure. Journal of Personality and Social Psychology, 37, 621-634.

Farmer, H., \& Vispoel, W. (1990). Attributions of female and male adolescents for real-life failure experiences. The Journal of Experimental Education, 58, 127-140.

Farmer, H., Vispoel, W., \& Maehr, M. (1991). Achievement contexts: Effect on achievement values and causal attribution. Journal of Educational Research, 85, 26-38.

Frieze, I., \& Snyder, H. (1980). Children's beliefs about the causes of success and failure in school settings. Journal of Educational Psychology, 72, 186-196.

Gobel, P., \& Mori, S. (2007). Success and failure in the EFL classroom: Exploring students' attributional beliefs in language learning. In L. Roberts, A. Gürel, S. Tatar, \& L. Martı (Eds.), EUROSLA Yearbook 7 (pp. 149-169). Amsterdam: John Benjamins Publishing Company.

Graham, S. (1991). A review of attribution theory in achievement contexts. Educational Psychology Review, 3, 5-39. 
Green, S., \& Salkind, N. (2005). Using SPSS for Windows and Macintosh: Analyzing and understanding data (4th ed.). Upper Saddle River, NJ: Pearson Education.

Heikkinen, A. (1999). A discourse analysis of success and failure accounts in learning English as a foreign language. Unpublished MA thesis, University of Jyväskylä, Finland. Retrieved from http://selene.lib.jyu.fi:8080/gradu/g/1570.pdf

Horwitz, E. K. (1988). The belief about language learning of beginning university foreign language students. The Modern Language Journal, 72, 283-294.

Hsieh, P., \& Schallert, D. L. (2008). Implications from self-efficacy and attribution theories for an understanding of undergraduates' motivation in a foreign language course. Contemporary Educational Psychology, 33, 513-532.

Isomöttönen, A. (2003). A discursive study of hard-of-hearing learners' explanations for failure and success in learning English as a foreign language. Unpublished MA thesis, University of Jyväskylä, Finland. Retrieved from http://selene.lib.jyu. fi:8080/gradu/g/0000417.pdf

Kalaja, P. (2004). "So maybe Freddie (Mercury) and his band mates really are to blame": Explaining success (or failure) in learning EFL. In K. Mäkinen., P. Kaikkonen., \& V. Kohonen (Eds.), Future perspectives in foreign language education (pp. 123-132). Oulu, Finland: Oulu University Press.

Kitayama, S., Markus, H. D., Matsumoto, H., \& Norasakkunkit, V. (1997). Individual and collective process in the construction of the self: Self-enhancement in the United States and self-criticism in Japan. Journal of Personality and Social Psychology, 72, 1245-1267.

Krueger, J. (1998). Enhancement bias in descriptions of self and others. Personality and Social Psychology Bulletin, 24, 505-516.

Little, A. (1985). The child's understanding of the causes of academic success and failure: A case study of British schoolchildren. British Journal of Educational Psychology, 55, 11-23.

Markus, H. D., \& Kitayama, S. (1991). Culture and self: Implications for cognition, emotion, and motivation. Psychological Review, 98, 224-253.

Marsh, H. (1984). Relations among dimensions of self-attribution, dimensions of self-concept, and academic achievements. Journal of Educational Psychology, 76, 1291-1308.

Meyer, J. P. (1980). Causal attribution for success and failure: A multivariate investigation of dimensionality, formation, and consequences. Journal of Personality and Social Psychology, 38, 704-718.

Meyer, J. P., \& Koelbl, S. (1982). Students' test performances: Dimensionality of causal attributions. Personality and Social Psychology Bulletin, 8, 31-36. 
Pancer, S. M. (1978). Causal attributions and anticipated future performance. Personality and Social Psychology Bulletin, 4, 600-603.

Pintrich, P.R. \& Schunk, D. (2002). Motivation in education: Theory, research, and application (2nd ed.). Upper Saddle River, NJ: Prentice-Hall.

Seegers, G., Van Putten, C., \& Vermeer, H. (2004). Effects of causal attributions following mathematics tasks on student cognitions about a subsequent task. The Journal of Experimental Education, 72, 307-328.

Sivanes, P. (2006). Cultural variability in parent and child achievement attributions: A study from Hong Kong. Educational Psychology, 26, 625-642.

Skehan, P. (1989). Individual differences in second-language learning. London: Edward Arnold.

Tabachnick, B., \& Fidell, L. (1996). Using multivariate statistics (3rd ed.). New York: Harper Collins.

Thepsiri, K., \& Pojanapunya, P. (2008). Science and engineering students' attributional beliefs of success and failure in the EFL classroom. Unpublished manuscript.

Travis, C., Burnett-Doering, J., \& Reid, P. (1982). The impact of sex, achievement domain and conceptual orientation on causal attributions. Sex Roles, 8, 443-454.

Tse, L. (2000). Student perceptions of foreign language study: A qualitative analysis of foreign language autobiographies. The Modern Language Journal, 84, 69-84.

Ushioda, E. (2001). Language learning at university: Exploring the role of motivational thinking. In Z. Dörnyei \& R. Schmidt (Eds.), Motivation and second language acquisition (pp. 93-126). Honolulu: University of Hawaii.

Vispoel, W., \& Austin, J. (1995). Success and failure in junior high school: A critical incident approach to understanding students' attributional beliefs. American Educational Research Journal, 32, 377-412.

Weiner, B. (1979). A theory of motivation for some classroom experiences. Journal of Educational Psychology, 71, 3-25.

Weiner, B. (1986). An attributional theory of motivation and emotion. New York: Springer-Verlag.

Weiner, B., Frieze, I., Kukla, A., Reed, L., Rest, S., \& Rosenbaum, R. (1971). Perceiving the causes of success and failure. Morristown, NJ: General Learning Press.

Williams, M., \& Burden, R. (1997). Psychology for language teachers. Cambridge: Cambridge University Press.

Williams, M., \& Burden, R. (1999). Students' developing conceptions of themselves as language learners. Modern Language Journal, 83, 193-201. 
Williams, M., Burden, R., \& Al-Baharna, S. (2001). Making sense of success and failure: The role of the individual in motivation theory. In Z. Dörnyei \& R. Schmidt (Eds.), Motivation and second language acquisition (pp. 171-184). Honolulu: University of Hawaii.

Williams, M., Burden, R., Poulet, G., \& Maun, I. (2004). Learners' perceptions of their successes and failures in foreign language learning. Language Learning Journal, 30, 19-29.

\section{Appendix}

\section{Translation of Questionnaire for Successful and Unsuccessful Learning Experience}

(This appendix is a combined questionnaire created for brevity's sake. In the actual study, the students in the success group and the failure group received questionnaires specifically related to either success or failure outcomes.)

\section{Personal Data}

Fill in the information which is appropriate to you

1. University:

Faculty: Department:

ID:

2. English Course studied in the 1st semester:

3. Sex: Male () Female ()

\section{Perceptions of English Language Learning}

1. Think about your past experience in the 1st semester English class. Try to remember a time in which you did particularly WELL/ POORLY on an activity in the class. The activity you are thinking of might be listed below. If so, circle the activity. If the activity is not listed below, circle the "other. .." and describe the activity in the space provided. Be sure to choose only ONE activity.

1. Reading texts using appropriate strategies

2. Answering comprehension questions

3. Learning vocabulary 
4. Understanding grammar

5. Translating texts and passages from English

6. Reading and summarizing texts

7. Reading quizzes and exams

8. Other reading activities

9. Understanding a listening passage using appropriate strategies

10. Listening and repetition/dictation

11. Listening and note taking

12. Listening quizzes and exams

13. Other listening activities

14. Giving a presentation and/or speech

15. Role play

16. Giving opinions/sharing ideas in class/groups

17. Answering teacher's questions

18. Speaking quizzes and exams

19. Other speaking activities

20. Writing a summary

21. Writing paragraphs

22. Writing diaries and/or portfolios

23. Writing a report

24. Writing quizzes and exams

25. Other writing activities

2. There may have been many reasons why you did (WELL, POORLY) on the activity you just circled. The following statements are possible reasons why you might have done (WELL, POORLY). Read each statement and fill in the appropriate space on the computer mark sheet to indicate the extent to which you agree or disagree with each statement.
A Strongly disagree
D Somewhat agree
B Disagree
E Agree
C Somewhat disagree
F Strongly agree

1. I have strong/weak skills in English.

2. I tried/didn't try very hard.

3. I used the right/wrong study or practice methods.

4. I had interest/no interest in the activity. 
5. I had good/bad luck.

6. The teacher's instruction was appropriate/inappropriate.

7. The task was easy/difficult.

8. I liked/didn't like the atmosphere of the class.

9. I had interest/no interest in getting a good grade.

10. I was well-prepared/ill-prepared.

11. I like/don't like English.

12. The level of the class was appropriate/inappropriate. 